\title{
Aggregation of coronary risk factors in families of men with fatal and non-fatal coronary heart disease
}

\author{
AILA M. RISSANEN AND ESKO A. NIKKIL $\ddot{A}$ \\ From the Third Department of Medicine, University of Helsinki, Helsinki, Finland
}

SUMMARY The occurrence of main coronary risk factors was assessed in the families of 211 men under age 56 from East Finland. Fifty men were survivors of a recent myocardial infarction, 55 had died of myocardial infarction, 53 suffered from uncomplicated angina, and 53 were healthy reference men. Familial hyperlipidaemia was twice and familial hypertension three times as common in case as in reference families; other risk factors were equally common in both. Familial hypercholesterolaemia was commonest in the families of men with fatal myocardial infarction, and multiple type familial hyperlipidaemia in those of men with angina. Any increase in familial aggregation of coronary heart disease was invariably paralleled by increased aggregation of hyperlipidaemia and hypertension, with the most impressive aggregation of both traits in case families with a maternal history of early coronary death. It is concluded that most of the familial aggregation of coronary heart disease is mediated by familial aggregations of hyperlipidaemia and hypertension.

Coronary heart disease, particularly when presenting early in life, tends to run in families (Slack and Evans, 1966; Phillips et al., 1974; Rissanen, 1979a, b). Some of this familial predisposition is mediated by familial resemblance in the major risk factors, such as hyperlipidaemia, hypertension, and diabetes. It is not known, however, how much of the familial component of the disease is accounted for by these risk factors. While some investigators have suggested that these factors alone may be responsible for all the familial trends observed (Stamler, 1973; Keys, 1975), others have concluded that most of these trends must be the result of factors as yet unidentified (Epstein, 1967a).

In the present investigation, the occurrence of coronary heart disease and its major risk factors have been recorded in the families of relatively young men from North Karelia, East Finland, where the incidence of premature coronary heart disease is the highest in the world (Epstein and Krueger, 1969). A previous report (Rissanen, 1979a) showed that coronary heart disease in this area has pronounced familial tendencies.

The present report represents an attempt to relate the familial trends of the disease to the occurrence of its major risk factors. Such information may help in improving the prospects of prevention of premature coronary heart disease in endemic areas. Received for publication 23 March 1979

\section{Subjects and methods}

\section{INDEX CASES}

The index cases of the study were 211 men under age 56 from two neighbouring communities in North Karelia. Fifty of these men had had a nonfatal and 55 a fatal myocardial infarction, 53 suffered from uncomplicated angina pectoris, and 53 were healthy reference men.

The 50 men with non-fatal myocardial infarction and 55 men who died were the consecutive men in the study communities who suffered non-fatal (survival 28 days or more) or fatal (survival less than 28 days) myocardial infarction in 1972 to 1974. The cases with angina pectoris were screened from occupational health examinations in local paper mills. The selected subjects had both an abnormal electrocardiogram at rest (Minnesota Code Nos. $1 \cdot 2-3,4 \cdot 1-3,5 \cdot 1-2,6 \cdot 1-2,7 \cdot 1-2$, or $8 \cdot 3)$ and classical anginal chest pain, but no history of myocardial infarction. The reference or control were free of any symptoms of coronary heart disease and had no signs of ischaemia in the resting electrocardiogram. They were selected from the same employee rosters as the patients with angina pectoris, with whom they were matched for age and occupation. Details of the selection process have been given earlier (Rissanen, 1979a).

The age distribution was similar in the four study 
groups. The average age was $48 \cdot 1$ years (range 22 to 55 years).

The medical records of the index cases were carefully reviewed. All living men and 148 spouses were examined by A.R. They were also interviewed by a psychologist and a dietitian as to their habits both before and after the diagnosis of coronary heart disease in the patient. Most patients had modified their habits temporarily after the diagnosis of coronary heart disease was made, but permanent changes were rare, except for smoking. One-quarter of the smokers had stopped smoking and another quarter had cut down their consumption. The mean change in weight since the first diagnosis of coronary heart disease was approximately $+1.5 \mathrm{~kg}$. The average intake of fat of the patients, estimated by the dietary recall method, was $137 \mathrm{~g} / \mathrm{d}, 80$ per cent of which was saturated animal fat.

A blood sample was obtained from the living men and all spouses. They were asked to maintain their customary diet, to abstain from alcohol, and to fast overnight (12 hours) before sampling.

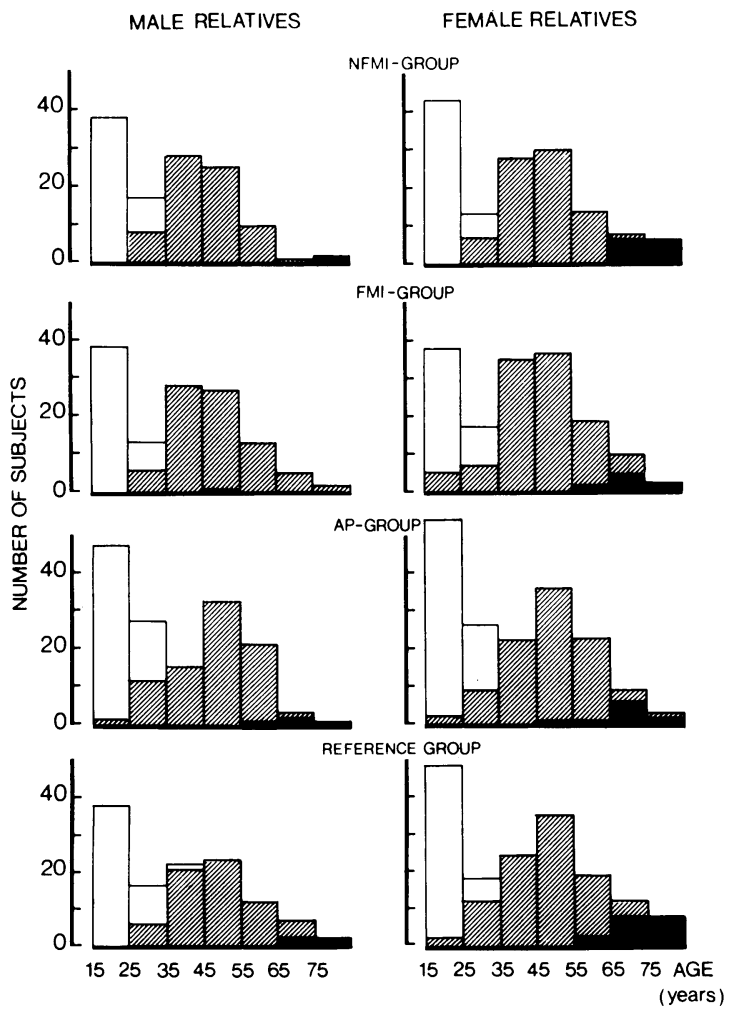

Fig. Age distribution of the study participants. $\square$ children, 跨 sibs, $\square$ parents. FMI, fatal myocardial infarction; NFMI, non-fatal myocardial infarction; $A P$, angina pectoris.
Table 1 Number of participants in different study groups

\begin{tabular}{lcccc}
\hline Study group & $\begin{array}{l}\text { Non-fatal } \\
\text { myocardial } \\
\text { infarction }\end{array}$ & $\begin{array}{l}\text { Fatal } \\
\text { myocardial } \\
\text { infarction }\end{array}$ & $\begin{array}{l}\text { Angina } \\
\text { pectoris }\end{array}$ & Reference \\
\hline Index cases & 50 & 55 & 53 & 53 \\
Fathers & 2 & 1 & 4 & 5 \\
Mothers & 14 & 9 & 10 & 17 \\
Brothers & 69 & 78 & 81 & 65 \\
Sisters & 75 & 104 & 94 & 93 \\
Sons & 46 & 46 & 63 & 50 \\
Daughters & 48 & 43 & 68 & 58 \\
Total relatives & 254 & 281 & 320 & 288 \\
\hline
\end{tabular}

Hypolipidaemic drugs were discontinued two weeks before sampling. Acutely ill subjects were rescheduled. No samples were drawn during the first three months after the acute myocardial infarction.

\section{RELATIVES}

The index cases were reported to have 522 deceased and 1280 living relatives aged 15 or over. The living relatives were sent a questionnaire that included questions on history of disease, physical complaints, medication, as well as on smoking and dietary habits. The relatives were also asked to report to local medical laboratories, where a blood sample was drawn after an overnight fast, and height, weight, and resting electrocardiogram were recorded. The laboratories had been instructed to help the respondents in filling in the questionnaire, which together with the serum sample and the recorded data was then forwarded to Helsinki for analysis.

Of the living relatives, $1143(89 \cdot 3 \%)$ complied with the study. The number of participants in different study groups is shown in Table 1 . The age distribution of the relatives was similar in all groups (Fig.). The mean age of both the brothers and sisters was 47.0 years, and that of the children $19 \cdot 3$ years.

The reliability of the questionnaire reports was evaluated by checking the information from 350 questionnaires against the records of hospitals and private physicians. The reported diagnoses of hypertension and diabetes could invariably be confirmed for the cases in which treatment for the ailment was also described. Therefore, the diagnoses of these diseases were accepted as reported if the treatment was also mentioned. All the reports of diagnosed coronary heart disease were, however, checked from earlier medical records or from death certificates.

To obtain information on changes in life style which the disease in the family might have caused, a sample of 145 relatives was invited to an interview and a clinical examination. Ninety-one per cent of 
them responded and were examined. Many relatives of the affected index cases expressed increased concern about their health, but actual changes in the habits of symptom-free subjects were negligible. Only the relatives who themselves had clinical coronary heart disease had modified their habits to a similar extent as the affected cases. When checked against the symptoms reported at the interview, the questionnaire reports on symptoms such as chest pain proved to be too unreliable for analysis.

\section{METHODS OF DATA ANALYSIS}

Serum cholesterol was determined by the method of Huang et al. (1961), and serum triglycerides by an autoanalyser according to Kessler and Lederer (1965). The coefficient of variation of the determinations during the two-year period of the study did not exceed 3 per cent. To minimise the effect of seasonal variation (Aromaa et al., 1975), sampling was discontinued for the summer months. All lipid values were adjusted to age 45 using regression equations derived from a large Finnish population study (Aromaa et al., 1975). The point for definition of hyperlipidaemia was set at the 90th centile of the age-adjusted values of the reference relatives. The limits are $8.81 \mathrm{mmol} / 1(340 \mathrm{mg} / 100 \mathrm{ml})$ for serum cholesterol in both sexes, and $2.31 \mathrm{mmol} / 1$ (205 $\mathrm{mg} / 100 \mathrm{ml})$ and $1.70 \mathrm{mmol} / 1(150 \mathrm{mg} / 100 \mathrm{ml})$ for serum triglycerides in men and women, respectively.

The criteria for familial aggregation used in this study were as follows: familial hyperlipidaemia was considered to be present when at least 30 per cent (and a minimum of two) of the relatives of the index case had hyperlipidaemia. The familial hyperlipidaemias were classified as hypercholesterolaemia (type II familial hyperlipidaemia), hypertrigly- ceridaemia (type IV familial hyperlipidaemia), or multiple type (combined) hyperlipidaemia according to the predominant type of hyperlipidaemia in the family members. The term familial hypertension was used when at least 30 per cent (and a minimum of two) of the adult relatives of the index case had a treated hypertensive disease.

Qualitative data were analysed by the $x^{2}$ test. For quantitative data, Student's $t$ test was used. Since the values of the members within a family are not independent of each other, significance tests will have to be interpreted as rough estimates of strength of association between the variables.

The groups with non-fatal myocardial infarction, fatal myocardial infarction, and angina pectoris will often be referred to jointly as case groups in the following text.

\section{Results}

\section{FREQUENCY OF RISK FACTORS}

\section{AMONG THE INDEX CASES}

The serum cholesterol and triglyceride levels of the patients with non-fatal myocardial infarction and angina pectoris were remarkably higher than those of reference men (Table 2). Hypercholesterolaemia and hypertriglyceridaemia were three to four times as common among patients as among the reference men and all the other main coronary risk factors, with the exception of overweight, were significantly more common among case than reference men (Table 3). Most notably hypertension was six times more common among the patients than the reference men. There were no appreciable differences in the prevalence of any of the risk factors between the patients with non-fatal myocardial infarction and those with angina pectoris.

Table 2 Mean levels of serum lipids and frequency of hyperlipidaemia ${ }^{\star}$ in members of different study groups

\begin{tabular}{|c|c|c|c|c|c|}
\hline & & $\begin{array}{l}\text { Serum } \\
\text { cholesterol } \\
(\text { mean } \pm S D, \mathrm{mmol} / \mathrm{l})\end{array}$ & $\begin{array}{l}\text { Serum } \\
\text { triglycerides } \\
(\text { mean } \pm S D, \text { mmol } / \mathrm{l})\end{array}$ & $\begin{array}{l}\text { Hyper- } \\
\text { cholesterolaemia } \\
(\%)\end{array}$ & $\begin{array}{l}\text { Hyper- } \\
\text { triglyceridaemia } \\
(\%)\end{array}$ \\
\hline $\begin{array}{l}\text { Index } \\
\text { cases }\end{array}$ & $\begin{array}{l}\text { Non-fatal myocardial infarction } \\
\text { Angina pectoris } \\
\text { Reference }\end{array}$ & $\begin{array}{l}7 \cdot 77 \pm 1 \cdot 57 \dagger \\
7 \cdot 55 \pm 1 \cdot 67 \dagger \\
6 \cdot 95 \pm 1 \cdot 23\end{array}$ & $\begin{array}{l}1.95 \pm 1.49 t \\
1.84 \pm 0.88 t \\
1.44 \pm 0.65\end{array}$ & $\begin{array}{l}32 \cdot 0 \ddagger \\
30 \cdot 2 \ddagger \\
11 \cdot 3\end{array}$ & $\begin{array}{c}32 \cdot 0 \ddagger \\
20 \cdot 8 \dagger \\
7 \cdot 5\end{array}$ \\
\hline Brothers & $\begin{array}{l}\text { Non-fatal myocardial infarction } \\
\text { Fatal myocardial infarction } \\
\text { Angina pectoris } \\
\text { Reference }\end{array}$ & $\begin{array}{l}7 \cdot 71 \pm 1 \cdot 29 t \\
7 \cdot 48 \pm 1 \cdot 61 \\
7 \cdot 24 \pm 1 \cdot 49 \\
7 \cdot 21 \pm 1 \cdot 34\end{array}$ & $\begin{array}{l}1.73 \pm 0.98 \\
1.69 \pm 1.04 \\
1.61 \pm 1.15 \\
1.49 \pm 0.70\end{array}$ & $\begin{array}{l}26 \cdot 1 \dagger \\
25 \cdot 6 \dagger \\
17 \cdot 3 \\
12 \cdot 3\end{array}$ & $\begin{array}{l}17 \cdot 4 \\
18 \cdot 0 \\
17 \cdot 3 \\
12 \cdot 3\end{array}$ \\
\hline Sisters & $\begin{array}{l}\text { Non-fatal myocardial infarction } \\
\text { Fatal myocardial infarction } \\
\text { Angina pectoris } \\
\text { Reference }\end{array}$ & $\begin{array}{l}7 \cdot 35 \pm 1 \cdot 99 \\
7.57 \pm 1 \cdot 66 t \\
7.36 \pm 1 \cdot 45 \\
7.03 \pm 1.49\end{array}$ & $\begin{array}{l}1.23 \pm 0.60 \\
1.31 \pm 0.61 \\
1.50 \pm 0.94 t \\
1.19 \pm 0.56\end{array}$ & $\begin{array}{l}12 \cdot 0 \\
21 \cdot 1 \dagger \\
12 \cdot 8 \\
7 \cdot 5\end{array}$ & $\begin{array}{l}13 \cdot 3 \\
18 \cdot 3 \\
30 \cdot 9 t \\
11 \cdot 8\end{array}$ \\
\hline Children & $\begin{array}{l}\text { Non-fatal myocardial infarction } \\
\text { Fatal myocardial infarction } \\
\text { Angina pectoris } \\
\text { Reference }\end{array}$ & $\begin{array}{l}5.58 \pm 1.00 \\
5.94 \pm 1 \cdot 14 \\
5.73 \pm 0.95 \\
5.50 \pm 0.95\end{array}$ & $\begin{array}{l}0.90 \pm 0.65 \\
1.00 \pm 0.50 \\
1.12 \pm 0.70 t \\
0.91 \pm 0.48\end{array}$ & $\begin{array}{c}5 \cdot 3 \\
12 \cdot 4 t \\
5 \cdot 3 \\
5 \cdot 6\end{array}$ & $\begin{array}{c}6 \cdot 4 \\
6 \cdot 7 \\
16 \cdot 0+ \\
7 \cdot 5\end{array}$ \\
\hline
\end{tabular}

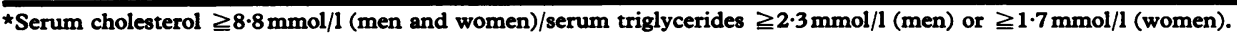

The values are adjusted to age 45 .

$+\mathrm{P}<0.05$ between case and reference group.

$\ddagger P<0.01$ between case and reference group. 
Table 3 Frequency of main risk factors in case and reference groups (\%)

\begin{tabular}{|c|c|c|c|c|c|c|}
\hline & & Hyperlipidaemia ${ }^{\star}$ & Hypertension & Clinical diabetes & Relative weight $\geqq 120$ & Regular smoking \\
\hline \multirow[t]{2}{*}{ Index cases } & Case & $43 \cdot 7 \ddagger$ & $41 \cdot 7 \ddagger$ & $9 \cdot 7$ & $19 \cdot 4$ & $72 \cdot 8 \dagger$ \\
\hline & Reference & $17.0^{\circ}$ & $7 \cdot 5^{\circ}$ & - & $13 \cdot 2$ & $49 \cdot 1$ \\
\hline \multirow[t]{2}{*}{ Brothers } & Case & $33 \cdot 8$ & 21.9 & $4 \cdot 4$ & $12 \cdot 7$ & 43.9 \\
\hline & Reference & $23 \cdot 1$ & $13 \cdot 8$ & - & $10 \cdot 8$ & $40 \cdot 0$ \\
\hline \multirow[t]{2}{*}{ Sisters } & Case & $32.6 t$ & $26 \cdot 4$ & 1.8 & $29 \cdot 0$ & $14 \cdot 7$ \\
\hline & Reference & $16 \cdot 1$ & $20 \cdot 4$ & $2 \cdot 2$ & 26.9 & $14 \cdot 0$ \\
\hline \multirow[t]{2}{*}{ Children } & Case & $1 \cap \cdot 2$ & 1.6 & - & $4 \cdot 5$ & 29.9 \\
\hline & Reference & $11 \cdot 1$ & - & - & 1.9 & $29 \cdot 5$ \\
\hline
\end{tabular}

«Age adjusted serum cholesterol $\geqq 8.8 \mathrm{mmol} / 1$ (men and women) and/or age adjusted serum triglycerides $\geqq 2.3 \mathrm{mmol} / 1$ (men) or $\geqq 1.7 \mathrm{mmol} / 1$ (women).

$+P<0.01$ between case and reference groups.

$\ddagger P<0.001$ between case and reference groups.

\section{FREQUENCY OF RISK FACTORS AMONG RELATIVES \\ Hyperlipidaemia}

The serum lipid patterns of the relatives in the various case groups differed considerably from each other. The serum cholesterol levels of the brothers were only slightly higher than those of the reference brothers, but the serum cholesterol levels of the sisters of the patients with fatal myocardial infarction were very high (Table 2). Hypercholesterolaemia was twice as common among the sisters and children of these men as it was among the sisters and children in other case groups. The highest serum triglyceride levels, on the other hand, were found among the relatives of patients with angina pectoris (Table 2). Among the sisters and children of these patients, the rate of hypertriglyceridaemia was more than twice that of the corresponding relatives of men with non-fatal mycoardial infarction and those with fatal myocardial infarction. Among the latter relatives, the rate of hypertriglyceridaemia was similar to that among the reference relatives.

Though the overall differences in the rate of hyperlipidaemia between case and reference relatives were small, family clusters of hyperlipidaemia were much more frequent in the case than in the reference group (Table 4). Familial hyperlipidaemia was present in one-third of case families but in only onesixth of reference families $(P<0.05)$. Familial hypercholesterolaemia was the predominant abnormality in the group with fatal myocardial in- farction, whereas familial multiple type hyperlipidaemia prevailed in other study groups.

\section{Hypertension}

Hypertension had been diagnosed in approximately one-fifth of the brothers and in a quarter of the sisters in all case groups (Table 3). These rates are 1.6 and 1.3 times the rates in the corresponding reference relatives $(P<0.05)$. Familial hypertension was, however, almost three times as common in case families as in reference families, occurring in 34 per cent of case families and in 13 per cent of reference families $(P<0.05)$.

\section{Other risk factors (Table 3)}

Clinical diabetes was present in 4 per cent of case brothers and in 2 per cent of both case and reference sisters. Overweight was equally common in case and reference relatives. Smoking habits were also similar in case and reference relatives. Diabetes, overweight, and smoking were equally common in the relatives of all case groups. None of these risk factors showed any distinct familial trends.

AGGREGATION OF RISK FACTORS IN RELATION TO FAMILIAL AGGREGATION OF CORONARY HEART DISEASE

Effect of parental history of coronary heart disease

There were 14 case families in which the mother of the index case had died of coronary heart disease before the age of 70 . Hypertension and hyper-

Table 4 Prevalence of familial hyperlipidaemia in different study groups

\begin{tabular}{|c|c|c|c|c|c|}
\hline \multirow[t]{2}{*}{ Study group } & \multirow[t]{2}{*}{ No. of families* } & \multicolumn{4}{|c|}{ Familial hyperlipidaemia } \\
\hline & & $\begin{array}{l}\text { Type II } \\
\text { Percent of families }\end{array}$ & Type IV & Multiple type & All types \\
\hline $\begin{array}{l}\text { Non-fatal myocardial infarction } \\
\text { Fatal myocardial infarction } \\
\text { Angina pectoris } \\
\text { Reference }\end{array}$ & $\begin{array}{l}47 \\
50 \\
53 \\
46\end{array}$ & $\begin{array}{l}10 \cdot 6 \\
28 \cdot 0+\ddagger \\
3 \cdot 8 \\
4 \cdot 3\end{array}$ & $\begin{array}{l}2 \cdot 1 \\
2 \cdot 0 \\
5 \cdot 7 \\
4 \cdot 3\end{array}$ & $\begin{array}{r}17 \cdot 2 \\
14 \cdot 0 \\
20 \cdot 7 \\
6 \cdot 5\end{array}$ & $\begin{array}{l}29 \cdot 8 \\
44 \cdot 0 \\
30 \cdot 2 \\
15 \cdot 1\end{array}$ \\
\hline
\end{tabular}

*Families with a minimum of two participating relatives.

$+P<0.01$ between the fatal myocardial infarction and the other case groups.

$\ddagger P<0.005$ between the fatal myocardial infarction and reference group. 
Table 5 Frequency of hypertension and hyperlipidaemia in case sibs according to parental history of coronary heart disease

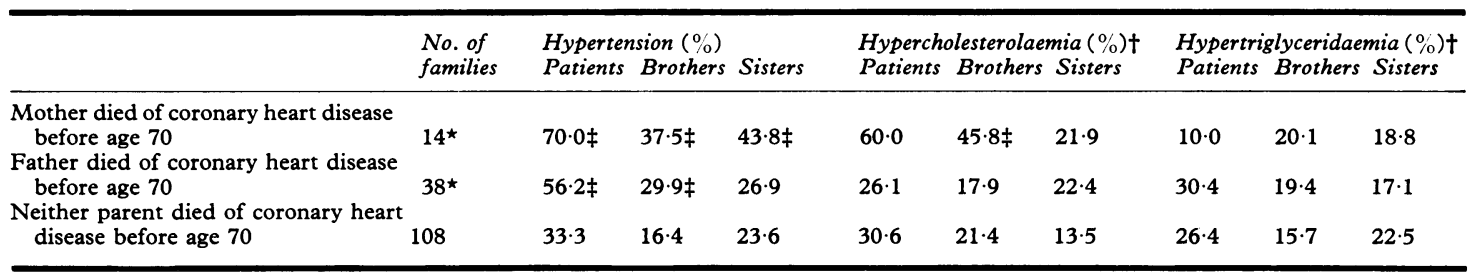

* Two families with parental history of coronary heart disease from both sides have been included in both categories.

†Age adjusted serum cholesterol $\geqq 8.8 \mathrm{mmol} / 1$ (men and women).

Age adjusted serum triglycerides $\geqq 2.3 \mathrm{mmol} / 1$ (men) or $\geqq 1.7 \mathrm{mmol} / 1$ (women).

$\ddagger P<0.05$ between the group with maternal/paternal history of coronary heart disease and the group without any parental history of coronary heart disease.

cholesterolaemia were very frequent in the offspring of these mothers (Table 5). Approximately one-half of their sons and daughters were hypertensive; one-half of the sons and one-fifth of the daughters also had hypercholesterolaemia.

The father of the index case had died of coronary heart disease before the age of 70 in 38 case families. Hypertension was somewhat more common in the offspring of these families than in the offspring of case families in which neither parent had died of coronary heart disease by age 70 (Table 5). A similar difference was not observed for hyperlipidaemia.

Hypertension and hyperlipidaemia were equally common in families with a parental history of fatal coronary heart disease over the age of 70 and in those without any parental history of coronary heart disease. The frequency of other coronary risk factors among the offspring was not related to parental coronary heart disease.

\section{Effect of family clustering of coronary heart disease} Hyperlipidaemia and hypertension were very common among the sibs affected by coronary heart disease. One-half of the diseased brothers and twothirds of the diseased sisters had hyperlipidaemia, and one-third of the brothers and three-quarters of the sisters were hypertensive. There was a gradual increase in the rates of these abnormalities among the unaffected sibs according to whether there were none, one, or several cases of coronary heart disease within the sibship. Thus, the symptom free sibs under age 45 in families with three or more affected sibs had, in the aggregate, $5 \cdot 2$ times more hypertension and 2.5 times more hyperlipidaemia than did the symptom-free subjects in families in which only the index case was affected $(P<0.01$ for both differences) (Table 6). Hypertension and hyperlipidaemia were equally common in young symptom-free subjects of all families with multiple affected sibs, irrespective of parental history of coronary heart disease. Of the 31 such families, familial hyperlipidaemia was present in 19 and familial hypertension in 18 ; both traits coincided in 11 of the families.

\section{SPOUSE CONCORDANCE FOR RISK FACTORS}

No significant correlations were found between the spouses for systolic or diastolic blood pressure levels, for serum cholesterol and triglyceride concentrations, or for relative body weights.

\section{Discussion}

Controversial views have been expressed concerning the causes of familial aggregation of coronary heart

Table 6 Frequency of hypertension and hyperlipidaemia in symptom-free case sibs under age 45 according to family history of coronary heart disease

\begin{tabular}{|c|c|c|c|c|c|c|}
\hline \multirow[b]{2}{*}{$\begin{array}{l}\text { Parental death from coronary heart disease } \\
\text { before age } 70\end{array}$} & \multicolumn{2}{|c|}{ Hypertension (\%) } & \multicolumn{2}{|c|}{ Hypercholesterolaemia $(\%) \star$} & \multicolumn{2}{|c|}{ Hypertriglyceridaemia $(\%)^{\star}$} \\
\hline & Yes & No & Yes & No & Yes & No \\
\hline \multicolumn{7}{|l|}{$\begin{array}{l}\text { No. of sibs with coronary heart disease in } \\
\text { family (excluding index case) }\end{array}$} \\
\hline $\begin{array}{l}0 \\
1 \\
2 \text { or more }\end{array}$ & $\begin{array}{l}11 \cdot 1 \\
23 \cdot 3 \\
37 \cdot 5 \dagger\end{array}$ & $\begin{array}{l}6 \cdot 7 \\
12 \cdot 2 \\
38 \cdot 9 \dagger\end{array}$ & $\begin{array}{l}21 \cdot 8 \\
18 \cdot 4 \\
33 \cdot 3\end{array}$ & $\begin{array}{l}14 \cdot 2 \\
22 \cdot 5 \\
18 \cdot 8\end{array}$ & $\begin{array}{l}14 \cdot 8 \\
28 \cdot 3 \\
33 \cdot 3 \dagger\end{array}$ & $\begin{array}{l}13 \cdot 8 \\
16 \cdot 0 \\
37 \cdot 5 \dagger\end{array}$ \\
\hline
\end{tabular}

$\star$ Age adjusted serum cholesterol $\geqq 8.8 \mathrm{mmol} / 1$. Age adjusted serum triglycerides $\geqq 2.3 \mathrm{mmol} / 1$ (men) or $\geqq 1 \cdot 7 \mathrm{mmol} / 1$ (women). $+\mathrm{P}<0.01$ between the groups with no and $2+$ affected sibs. 
disease, itself a well-documented phenomenon (Slack and Evans, 1966; Phillips et al., 1974; Rissanen, 1979a, b). Only a few studies have, in fact, proceeded beyond the point of merely establishing that such aggregation does occur.

From what is known it appears that high levels of serum cholesterol, blood pressure, and blood glucose play some-as yet undefined-roles in determining clustering of coronary heart disease within families (Deutscher et al., 1969).

If these correctable risk factors were major causes of the familial pattern of coronary heart disease, such a disease pattern could perhaps be eliminated by early detection and appropriate treatment of the susceptible individuals. Such a possibility warrants special consideration in areas with high rates of premature coronary heart disease.

We have studied the extent and nature of familial aggregation of coronary heart disease in North Karelia, Eastern Finland, an area which has the world's gloomiest record of coronary heart disease morbidity. A previous article in this series (Rissanen, 1979a) confirmed the extraordinarily high overall rate of coronary heart disease in this area. It also described pronounced familial aggregation of coronary heart disease in the cohort of the present study.

The objective of the present report was to provide information about the risk factors associated with the familial aggregation of coronary heart disease observed previously. The results strongly suggest that most of this aggregation was attributable, or at least related to, familial aggregation of hypertension and hyperlipidaemia. Clustering of coronary heart disease within families was almost invariably accompanied by familial clustering of one of the two traits, or, when there was pronounced clustering of coronary heart disease, by distinct familial clustering of both.

The aggregation of these risk factors was most impressive in families in which the mother had died of coronary heart disease before age 70 . There was considerable clustering of hypertension in all these families, in almost two-thirds accompanied by pronounced clustering of hyperlipidaemia. It is likely that the affected mothers possessed and passed to their offspring a set of potent determinants of early-onset hypertension and hyperlipidaemia. The present findings are consistent with those of a recent report from Norway which suggested that familial hypertension may be a major determinant of coronary heart disease in young women (Förde and Thelle, 1977). The importance of familial hypercholesterolaemia to coronary heart disease in women is also well documented (Slack and Nevin, 1968).
The overall rates of the traditional risk factors were not remarkable among the members of families in which the father had died of coronary heart disease before age 70 . In fact, the clustering of coronary heart disease observed in these families appeared to some extent to exceed that expected on the basis of the prevalence of the major risk factors. If some of the clusters of coronary heart disease in these families had arisen from chance alone, and even if the failure to detect an excess of the major risk factors had in part been the result of methodological deficiencies, the possibility remains that in some of these families factors other than those studied here were responsible for the observed aggregation of coronary heart disease. A similar suggestion was put forward by the investigators in Tecumseh (Deutscher et al., 1970). They concluded that any clustering of coronary heart disease in families of men who developed coronary heart disease past age 65 must be the result of factors as yet unidentified. Such possible predisposing factors include familial similarities in the structure of coronary arteries (Pesonen et al., 1975), body build (McKusick, 1965), behaviour (Bortner et al., 1970), smoking habits (Thomas, 1968), and in other shared environmental influences (Sholtz et al., 1975).

There were some differences in the serum lipid profiles between the relatives of the various case groups. A pronounced excess of hypercholesterolaemia was found among the relatives of the index cases of fatal myocardial infarction, and a similar excess of hypertriglyceridaemia was detected among the relatives of the cases with angina. These variations in the lipid patterns may be related to the differences in the clinical patterns of coronary heart disease of the various case groups observed earlier (Rissanen, 1979a).

It was shown that predominantly fatal forms of coronary heart disease aggregated in families of the patients with fatal myocardial infarction, whereas uncomplicated angina was the predominant form of coronary heart disease in families of the patients with angina pectoris. It may therefore be postulated that hypercholesterolaemia favours the development of fatal coronary heart disease, whereas hypertriglyceridaemia mostly favours the development of angina. In support of this, several earlier studies have suggested that the serum cholesterol level is less strongly related to angina than to other clinical manifestations of coronary heart disease (Lawry et al., 1957; Paul et al., 1963; Chapman and Massey, 1964; van Buchem, 1967). It has also been reported earlier that the highest serum cholesterol levels tend to be associated with fatal coronary heart disease (Deutscher et al., 1970; Tibblin et al., 1975). 
Once familial aggregation of the risk factors has been shown, the important issue is to decide whether this aggregation is caused by common genes or shared environmental influences. Though the present study was not designed to explore the aetiologies of the coronary risk factors, some limited observations on this issue can be made. First, the aggregation of hyperlipidaemia and hypertension in case families with a history of premature parental death from coronary heart disease suggests transmission by genetic factors. The rate of 50 per cent among the adult family members could hardly be explained otherwise. Second, environmental effects can be discounted as major causes of the familial trends observed, because there were no obvious similarities between spouses for any of the factors studied. Such similarities were found, on the other hand, within sibships even when the sibs lived far apart.

It is difficult, however, to disentangle genetic effects from familial environmental influences. Moreover, the response to environment may be genetically determined. A weak environmental effect may become a potent predisposing factor when superimposed on a susceptible phenotype. An interaction of genetic and environmental effects could thus account for most of the familial aggregation observed.

This kind of interaction could also explain the unusually high overall serum cholesterol levels of the study population. Finns, unlike most other populations studied, show a significant correlation between the dietary fat intake and the serum cholesterol level (Räsänen et al., 1978). It is possible that the high serum cholesterol concentrations of Finns represent a genetically determined sensitivity to the typical Finnish diet, with its high content of saturated fat.

The impact of smoking should be viewed against the background set by the high serum cholesterol levels. Apart from the 'normal' Finnish serum cholesterol level, heavy smoking was the only major risk factor in one-third of the diseased index cases. We have also found earlier (Rissanen and Nikkilä, 1977) that smoking is an independent modifier of the development of coronary heart disease in the North Karelian families even in the presence of major familial risk factors.

The cross-sectional approach of comparing abnormality rates in first degree relatives of coronary patients with the rates in reference relatives is prone to several methodological deficiencies (Epstein, 1964). First, it is likely that the relatives of patients are more aware of the disease and therefore show excessive concern over health. However, it has been shown earlier (Honeyman et al., 1968) that despite the concern shown, the relatives of coronary patients do little to improve their health. This fact could be verified also at the clinical examinations performed on the relatives of the present study. Second, a considerable bias may have been introduced by the selective removal from the study cohort of persons who died of premature coronary heart disease. Such persons are likely to harbour one or another of the major risk factors (Epstein, 1967b). Loss of brothers may have influenced the results. On the other hand, the mortality of sisters was still low, and thus not likely to be a major source of error.

The findings of the present study have established that most of the familial susceptibility to coronary heart disease is mediated by familial aggregation of hypertension and hyperlipidaemia. An early detection and an appropriate treatment of these abnormalities would probably eliminate the risk and prevent or delay the subsequent development of the disease. Therefore, apart from active preventive efforts, relatives of patients with premature coronary heart disease should be submitted to close clinical surveillance for any emerging abnormality.

This work was supported by grants from Finnish State Medical Research Council, from the Yrjö Jahnsson Foundation, and from the Finnish Heart Association. Most data analysis of the present study was performed during the first author's term as visiting fellow, Epidemiology Branch, Division of Heart and Vascular Diseases, NHBLI, Bethesda, Maryland, USA.

\section{References}

Aromaa, A., Björksten, F., Eriksson, A. W., Maatela, J., Kirjarinta, M., Fellman, J., and Tamminen, M. (1975). Serum cholesterol and triglyceride concentrations of Finns and Finnish Lapps. I. Basic data. Acta Medica Scandinavica, 198, 13-22.

Bortner, R. W., Rosenman, R. H., and Friedman, M. (1970). Familial similarity in a pattern A behaviour. Fournal of Chronic Diseases, 23, 39-43.

Chapman, J. M., and Massey, F. J., jun. (1964). The interrelationship of serum cholesterol, hypertension, body weight, and risk of coronary disease: results of the first ten years follow-up in the Los Angeles Heart Study. Fournal of Chronic Diseases, 17, 933-949.

Deutscher, S., Epstein, F. H., and Keller, J. B. (1969). Relationship between familial aggregation of coronary heart disease and risk factors in the general population. American fournal of Epidemiology, 89, 510-520.

Deutscher, S., Ostrander, L. D., and Epstein, F. H. (1970). Familial factors in premature coronary heart disease-a preliminary report from the Tecumseh Community Health Study. American fournal of Epidemiology, 91, 233-237.

Epstein, F. H. (1964). Hereditary aspects of coronary heart disease. American Heart fournal, 67, 445-456.

Epstein, F. H. (1967a). Risk factors in coronary heart disease. Environmental and hereditary influences. Israel fournal of Medical Sciences, 3, 594-607. 
Epstein F. H. (1967b). Some uses of prospective observations in the Tecumseh Community Health Study. Proceedings of the Royal Scoiety of Medicine, 60, 56-60.

Epstein, F. H., and Krueger, D. R. (1969). The changing incidence of coronary heart disease. In Modern Trends in Cardiology, vol. 2, p. 17, ed A. Morgan Jones. Butterworths, London.

Förde, O. H., and Thelle, D. S. (1977). The Tromsö heart study: risk factors for coronary heart disease related to the occurrence of myocardial infarction in first degree relatives. American fournal of EpidemiologyI 105, 192-199.

Honeyman, M. S., Rappaport, H., Reznikoff, M., Glueck, B. C., and Eisenberg, H. (1968). Psychological impact of heart disease in the family of the patient. Psychosomatics, 9, 34-37.

Huang, T., Chen, C., Wefler, V., and Raftery, A. (1961). A stable reagent for the Liebermann-Burchard reaction. Application to rapid serum cholesterol determination. Analytical Chemistry, 33, 1405-1406.

Kessler, G., and Lederer, H. (1965). Fluorometric measurement of triglycerides. In Automation in Analytical Chemistry, Technicon Symposium, p. 341, ed L. T. Skeggs, jun. Mediad, New York.

Keys, A. (1975). Coronary heart disease-the global picture. picture. Atherosclerosis, 22, 149-192.

Lawry, E. Y., Mann, G. V., Peterson, A., Wysocki, A. P., O'Connel, R., and Stare, F. J. (1957). Cholesterol and beta lipoprotein in the serum of Americans. American fournal of Medicine, 22, 605-623.

McKusick, V. A. (1965). Coronary artery disease. In Genetics and Epidemiology of Chronic Diseases, p. 133. US PHS Publ. No. 1163, Washington, DC.

Paul, O., Lepper, M. H., Phelan, W. H., Dupertuis, G. W., McMillan, A., McKean, H., and Park, H. (1963). A longitudinal study of coronary heart disease. Circulation, 28, 20-31.

Pesonen, E., Norio, R., and Sarna, S. (1975). Thickenings in the coronary arteries in infancy as an indication of genetic factors in coronary heart disease. Circulation, 51, 218-225.

Phillips, R. L., Lilienfeld, A. M., Diamond, E. L., and Kagan, A. (1974). Frequency of coronary heart disease and cerebrovascular accidents in parents and sons of coronary heart disease index cases and controls. American fournal of Epidemiology, 100, 87-100.
Räsänen, L., Wilska, M., Kantero, R.-L., Näntö, V., Ahlström, A., and Hallman, N. (1978). Nltrition survey of Finnish rural children. IV. Serum cholesterol values in relation to dietary variables. American fournal of Clinical Nutrition, 31, 1050-1056.

Rissanen, A. M. (1979a). Familial aggregation of coronary heart disease in a high incidence area (North Karelia, Finland). British Heart fournal, 42, 294-303.

Rissanen, A. M. (1979b). Familial occurrence of coronary heart disease: effect of age at diagnosis. American fournal of Cardiology, 44, 60-66.

Rissanen, A. M., and Nikkilä, E. A. (1977). Coronary artery disease and its risk factors in families of young men with angina pectoris and in controls. British Heart fournal, 39, 875-883.

Sholtz, R. I., Rosenman, R. H., and Brand, R. J. (1975). The relationship of reported parental history to the incidence of coronary heart disease in the Western Collaborative Group Study. American fournal of Epidemiology, 102, 350-356.

Slack, J., and Evans, K. A. (1966). The increa sed ri :k of death from ischaemic heart disease in first degree relatives of 121 men and 96 women with ischaemic heart disease. Fournal of Medical Genetics, 3, 239-257.

Slack, J., and Nevin, N. C. (1968). Hyperlipidemic xanthomatosis I: Increased risk of death from ischemic heart disease in first-degree relatives of 53 patients with essential hyperlipidemia and xanthomatosis. Fournal of Medical Genetics, 5, 4-8.

Stamler, J. (1973). Epidemiology of coronary heart disease. Medical Clinics of North America, 57, 5-46.

Thomas, C. B. (1968). On cigarette smoking, coronary heart disease, and the genetic hypothesis. Fohns Hopkins Medical fournal, 122, 69-76.

Tibblin, G., Wilhelmsen, L., and Werkö, L. (1975). Risk factors for myocardial infarction and death due to ischemic heart disease and other causes. American fournal of Cardio$\log y, 35,514-522$.

van Buchem, F. S. P. (1967). Serum lipids, nutrition and atherosclerotic complications in man. Actz Medica Scandinavica, 181, 403-416.

Requests for reprints to Dr A. Rissanen, Third Department of Medicine, University of Helsinki, 00290 Helsinki 29, Finland. 